\title{
SAMPLING AND FAUNAL TURNOVER IN EARLY EOCENE MAMMALS
}

\author{
CATHERINE BADGLEY and PHILIP D. GINGERICH \\ Museum of Paleontology, University of Michigan, Ann Arbor, MI 48109 (U.S.A.)
}

(Received July 21, 1987)

\begin{abstract}
Badgley, C. and Gingerich, P. D., 1988. Sampling and faunal turnover in Early Eocene mammals. Palaeogeogr., Palaeoclimatol., Palaeoecol., 63: 141-157.

Faunal turnovers in the fossil record are episodes of synchronous appearance and disappearance of species from a community, often resulting in net change in species richness. We studied the biostratigraphic record of faunal turnover involving early Wasatchian (early Eocene) mammals from the Clark's Fork Basin, Wyoming, U.S.A. Two faunal turnovers occur in this record - one at the base of the Wasatchian, comprised mainly of appearances of taxonomically and ecologically distinctive species, and a later one, Biohorizon A of Schankler (1980), comprised mainly of disappearances, especially of carnivorous species. This study focuses on Biohorizon A.

In the record of the Clark's Fork Basin, Biohorizon A may be an artifact of sampling. Sample size and species richness are highly correlated $(r=0.95)$ throughout this record. Moreover, sample size and species richness fluctuate markedly between successive stratigraphic intervals; peaks of appearances coincide with large sample sizes and peaks of disappearances with low sample sizes. The peaks and valleys in fossil productivity over time mask the real timing of appearances and disappearances of species. Changes in fossil productivity in the stratigraphic section may result from changes in exposure area, taphonomic factors, or ecological factors.

Evaluation of the effects of sampling is a necessary prerequisite for investigating the chronological and ecological significance of faunal turnovers.
\end{abstract}

\section{Introduction}

Faunal turnover refers to change in species composition of a fauna through the disappearance of some species and the appearance of other species. The disappearances may be local or global extinctions or may be only temporary disappearances; the appearances may be local or global first appearances or else reappearances of taxa that were formerly present. The fossil record abounds in faunal turnovers. They mark many chronological boundaries in the geological time scale. The major faunal turnovers - those of broad taxonomic scope and wide geographic coverage - are important as events in ecological and evolutionary history and as guides to regional correlation.
Faunal turnovers have been recognized over a considerable range of spatial and temporal scales. At a large scale, for example, Kitchell and Carr (1985) modelled diversification of and interactions among three Phanerozoic marine faunas (at the family level) as compiled by Sepkoski (1981). At a small scale, for example, Schankler (1980) identified episodes of extinction and immigration within the mammalian fauna for part of the early Eocene, within part of a depositional basin. At an intermediate scale, for example, Webb (1984) described origination and extinction within the mammalian fauna of North America during the middle to late Miocene and also the interchange of mammals between North and South America during the late Neogene. 
While the essence of faunal turnovers is the synchronous appearance and disappearance of taxa, two other aspects are relevant to understanding their mechanism and significance: net change and rate of change in the number of species present, that is, species richness. Faunal turnovers may be rapid (from $10^{3}$ to $10^{5} \mathrm{yr}$ ) to slow (some $10^{6} \mathrm{yr}$ ) in geological time. Some paleontologists have considered different causal mechanisms to pertain to slow versus rapid faunal turnovers (e.g., Olson, 1980; Vrba, 1985), although this issue remains open. In many clear instances of turnover, neither the rate of change of species richness nor the rates of species appearances and disappearances can be specified precisely, owing to the absence of absolute chronological markers. A substantial degree of faunal turnover could result in a net change of zero in species richness, but the usual pattern involves a net increase or decrease. Webb (1984) proposed two types of faunal turnover - those in which extinctions outnumber originations and those in which originations outnumber extinctions. These types, distinguished on the basis of change in species richness, are associated with different environmental causes.

The present paper illustrates the role of sample size in the record of an apparent faunal turnover in the early Eocene history of mammals from the Bighorn Basin, Wyoming (U.S.A.). Sample size reflects taphonomic or ecological influences on the fossil record. This aspect of faunal turnover is rarely given explicit consideration in evaluation of the rate or the putative mechanisms of faunal change. In the example presented here, we find a close correlation between the components of faunal turnover and changes in sample size through the stratigraphic section.

\section{Background}

The Bighorn Basin of northwestern Wyoming, U.S.A. (Fig.1), records a set of major and minor faunal turnovers in the early Cenozoic history of mammals from western North America. Major faunal turnovers correspond to the transitions between the North American land mammal ages (e.g., Puercan, Clarkforkian, Wasatchian). Minor faunal turnovers often correspond to faunal zones within land mammal ages. Faunal zones are typically based on stratigraphic ranges of one to a few taxa, while faunal turnovers are based on surveys of the whole fauna.

Here, we discuss the record of a faunal turnover in early Wasatchian (early Eocene)

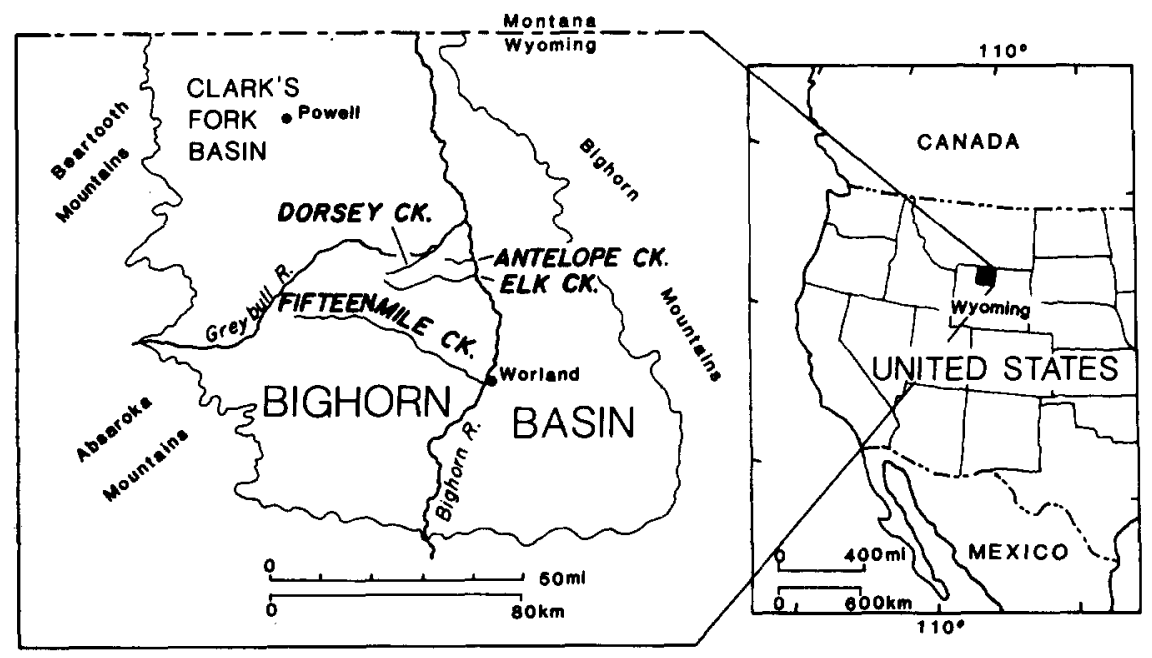

Fig.1. Location of the Bighorn Basin in northwestern Wyoming, western United States with enlargement of the Bighorn Basin. The Clark's Fork Basin is the northwestern portion of the Bighorn Basin. The study area of Schankler (1980) centers around Elk Creek, that of Bown centers around Fifteen Mile Creek. 


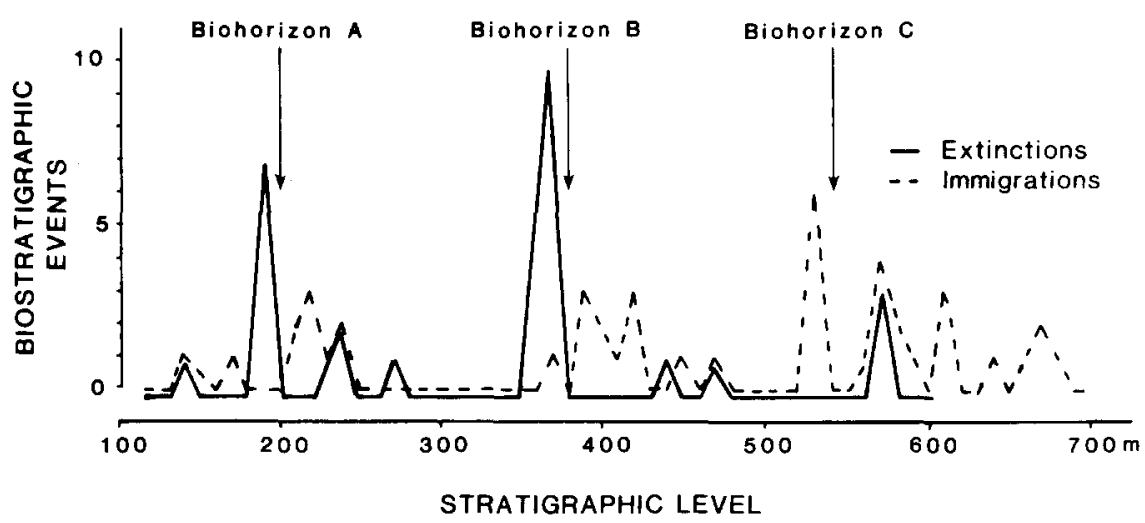

Fig.2. Three episodes of faunal turnover in early Eocene mammals, as identified by the frequency of "extinctions" (disappearances, this paper) and "immigrations" (appearances, this paper) versus stratigraphic level in the central Bighorn Basin. The Clarkforkian-Wasatchian boundary is below the lowest level represented here. Redrawn from Schankler (1980).

deposits of the Clark's Fork Basin, in the northwestern corner of the Bighorn Basin. We refer to this turnover as "Biohorizon A", a name proposed by Schankler (1980). Schankler formulated Biohorizon $\mathrm{A}$ on the basis of the biostratigraphy of fossil localities in the Willwood Formation of the central Bighorn Basin, specifically, in an area of about $650 \mathrm{~km}^{2}$ along Elk, Antelope, Dorsey, and Fifteen Mile Creeks (Fig.1). Schankler (1980) recognized three episodes of faunal turnover in early Wasatchian deposits of the central Bighorn Basin (about $100 \mathrm{~km}$ southwest of the Clark's Fork Basin): Biohorizons A, B, and C (Fig. 2). He established these by plotting first and last appearances and a few reappearances of taxa in $600 \mathrm{~m}$ of Wasatchian section. The three biohorizons mark short intervals with a high frequency of "extinctions" and "immigrations", relative to longer intervals with less faunal change. Biohorizon A comprises a large peak of extinctions and a minor peak of immigrations.

As defined by Schankler (1980), Biohorizon A marks the boundary between the lower and upper units of the Haplomylus-Ectocion Range-Zone and also divides the lower and middle Graybullian sub-ages of the Wasatchian land mammal age. Gingerich (e.g., 1983a) regards Biohorizon $A$ as the transition from Sandcouleean (early Wasatchian) to Graybullian (middle Wasatchian) sub-ages.

In the Clark's Fork Basin, a minor faunal turnover, involving many of the same taxa, occurs in the same relative position as Schankler's Biohorizon A. We have provisionally considered this turnover to be the same biochronological event and have called it Biohorizon A (e.g., Gingerich, 1982, 1983b, 1985; Gunnell, 1985). By correlation to the magnetic polarity time scale of Berggren et al. (1978), Biohorizon $\mathrm{A}$ is estimated to lie between 51.5 and 52.0 myr in the Clark's Fork Basin (Gingerich, 1982). Below, we present the biostratrigraphic data that define Biohorizon A in the Clark's Fork Basin, describe the geological context of Wasatchian fossil assemblages, and evaluate the pattern of fossil productivity through the Wasatchian in relation to the pattern of biostratigraphic change.

\section{Materials and methods}

Data for this study come from two sources, representing broad-scale and fine-scale records of faunal change in the Clark's Fork Basin. The first set of data consists of all mammalian specimens catalogued at the University of Michigan Museum of Paleontology (UMMP) from the Wasatchian portion of the Clark's Fork Basin. Catalogued specimens collected between 1975 and 1985 by Gingerich and coworkers form the basis for determining biostratigraphic ranges of early Wasatchian mammalian species. In this sample, specimens were 
originally collected from one or more horizons within a restricted stratigraphic interval in a limited geographic area, designated a locality. Localities were tied to local stratigraphic sections and their stratigraphic positions recorded to the nearest $5 \mathrm{~m}$. This broad-scale record spans $700 \mathrm{~m}$ of section. The second set of data consists of mammalian fossils collected from seven fossiliferous horizons that span an interval of $40 \mathrm{~m}$ encompassing Biohorizon A. These fine-scale samples were collected by Badgley and co-workers during the field seasons of 1984 and 1985 . The stratigraphic placement of collecting horizons was measured to the nearest $0.5 \mathrm{~m}$.

The two data sets differ in their representation of the original fossil assemblages. In the field, fossil assemblages of the Willwood formation occur as a scatter of disarticulated and often incomplete elements, usually weathered from identifiable stratigraphic horizons that produce fossils along much of their exposure (Bown and Kraus, 1981b; Winkler, 1983; this paper). The broad-scale, catalogued sample from the Wasatchian is a selective culling of these surface fossil assemblages. Jaws are the most numerous catalogued items, isolated teeth of assorted taxa are next in abundance, and non-mammalian remains and mammalian postcranials are the least numerous catalogued items. Material collected but not catalogued from a locality is assigned the status "miscellaneous" and then given a single catalogue number for each collecting visit. The "miscellaneous" may include non-mammal material (e.g., reptile, fish, plant, mollusc), postcranials, isolated teeth of well-known taxa, and incomplete jaws of taxa already abundantly represented by jaws. In the finescale study of Biohorizon A, all fossil material identifiable as to skeletal part or taxon was collected. Data presented here represent all gnathic and dental material of mammals; of this material, the more complete jaws are catalogued individually in the UMMP catalogue. Thus, there is a small amount of overlap in the two sets of data.

The geological context of fossil assemblages in the Biohorizon A study area was assessed from a detailed stratigraphic study of fossiliferous as well as non-fossiliferous units. Sedimentary environments were evaluated on the basis of field documentation of lithologies from hand specimens, vertical facies variation in measured sections, and lateral facies variation in laterally correlated sections. On the basis of personal observations and catalogued records of the UMMP, we conclude that the geological context of other early Wasatchian localities in the Clark's Fork Basin is broadly similar to that of fossiliferous horizons in the Biohorizon A study area.

We constructed a biostratigraphic range chart for early Wasatchian mammals of the Clark's Fork Basin based on the broad-scale catalogued records of the UMMP (Fig.3). The documented interval spans $700 \mathrm{~m}$, from just below the Clarkforkian-Wasatchian boundary to $200 \mathrm{~m}$ below the top of the section. The quality of the biostratigraphic record for each species was determined from the sample sizes for each $20-\mathrm{m}$ stratigraphic interval and from

Fig.3. Biostratigraphic range chart of early Wasatchian mammals from the Clark's Fork Basin. Mammals are listed by order, with Condylarthra divided into herbivorous and carnivorous subunits. Excluded are mammalian orders comprising predominantly small taxa (less than $100 \mathrm{~g}$ estimated body weight), because remains of such taxa are generally too rare to be informative of the timing of faunal change. Species names, ranges, and phyletic transitions are taken principally from the UMMP catalogue records as of 1985, with additional information from Gingerich and Gunnell (1979), Gingerich (1983b), Gunnell (1985), and Ivy (1982). The quality of the record for each species is indicated by the width of the line. Heavy lines indicate records of good quality. Lines of medium width indicate records of medium quality. Thin lines indicate "spotty" records. (See text for further explanation.) Gaps of $200 \mathrm{~m}$ or greater are represented as blank areas with a question mark. Single specimens with large gaps below or above are marked as an $x$. For species represented by lines, small horizontal ticks at the base (resp. top) indicate the first (resp. last) records in the Clark's Fork Basin. The absence of a tick at the left (resp. right) indicates that the record continues below (resp. above) the interval represented. Numbers at the left indicate the stratigraphic position (in meters) at which the species is first recorded, if lower than the Clarkforkian-Wasatchian boundary. The stippled band marks Biohorizon $\mathrm{A}$. 


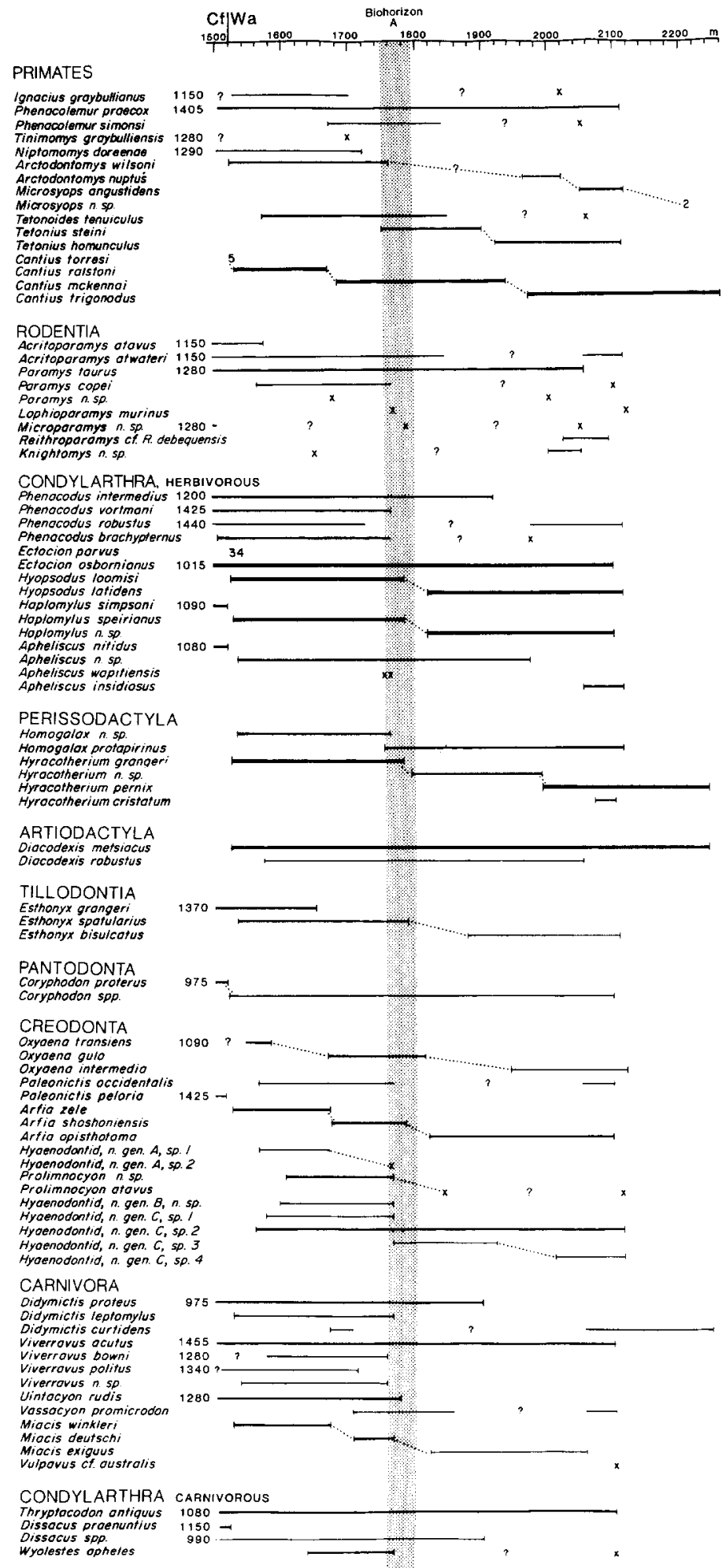


the size of gaps in each species' record, mainly within the interval 1520-1755 m (below Biohorizon A). A "good" record has predominantly large samples with small gaps: these ranged from 3 to 297 catalogued specimens per $20-\mathrm{m}$ interval, with gaps of less than $20 \mathrm{~m}$. A "medium" record has small to moderate sample sizes with more and larger gaps: these ranged from 0 to 19 catalogued specimens, with gaps of from 20 up to $130 \mathrm{~m}$, but mostly less than $50 \mathrm{~m}$. A "spotty" record has small sample sizes fewer than 12 catalogued specimens per $20-\mathrm{m}$ interval - with gaps of 50-200 m. Taxa with gaps of up to $200 \mathrm{~m}$ (not indicated in Fig. 3) were considered to be present but not recorded (yet) by fossils. For taxa with gaps of greater than $200 \mathrm{~m}$ in Fig.3, the gaps were recorded for consideration as possible local extinctions and reappearances. For taxa represented by from one to a few specimens for their entire record, all individual specimens were plotted. In addition to the biostratigraphic data, we compiled the number of localities and the number of catalogued specimens for each $20-\mathrm{m}$ interval.

Faunal change in Fig. 3 is summarized in several ways. We divided the $700-\mathrm{m}$ section into 20-m increments (e.g., 1520-1535, 1540-1555, etc.). We computed species richness for each 20-m interval, a count of all taxa with records somewhere in the interval. We defined appearances and disappearances for each interval in two parallel ways, as follows. Appearances included (1) the number of first records in the Clark's Fork Basin, or (2) the number of first records plus the number of taxa that "reappear" after a gap of $200 \mathrm{~m}$ or more. Disappearances included (1) the number of last records, or (2) the number of last records (terminal disappearances) plus the number of taxa with ensuing gaps of $200 \mathrm{~m}$ or more (temporary disappearances). Two taxa are known by specimens that occur within only one interval. Such taxa were counted as appearing and disappearing within the same interval. A few taxa are represented by two specimens separated by gaps of $200 \mathrm{~m}$ or more; under the second method of tallying appearances and disappear- ances, each specimen is counted as both an appearance and a disappearance. Speciation by anagenesis involves 33 of the 87 species (38\%) in Fig.3 (Gingerich and Gunnell, 1979; Gingerich, 1980, 1983b, 1985, 1986; Gunnell, pers. comm., 1986). Changes in species composition resulting from anagenesis were not counted as either appearances or disappearances.

\section{Results}

\section{The Wasatchian record of the Clark's Fork Basin}

The biostratigraphy of mammals from early Wasatchian sediments of the Clark's Fork Basin is the basis for identifying Biohorizon A. Figure 3 documents the broad-scale stratigraphic ranges of 87 species known from early Wasatchian localities. The interval recognized as Biohorizon A occurs between 1750 and $1795 \mathrm{~m}$. Table I summarizes the principal changes in species composition. Three species appear near the base of the interval. Eight species disappear (terminal disappearances) within this interval; six of these eight are carnivorous mammals. Six species have gaps of greater than $200 \mathrm{~m}$ beginning within this interval (temporary disappearances); remains of these species occur again between 1970 and $2100 \mathrm{~m}$. One plausible interpretation of these gaps is temporary extinction and later re-entry of these lineages in the Clark's Fork Basin, an interpretation favored by Schankler (1981) for the phenacodontids in the central Bighorn Basin. The quality of the record for each species involved in the turnover at Biohorizon $\mathrm{A}$ is also indicated in Table I. Ten of the 17 species have spotty records; the remainder have records of medium quality. In sum, disappearances outnumber appearances, a pattern that also characterizes Schankler's Biohorizon A (Fig.2).

There are additional changes in faunal composition at Biohorizon A (Table II) that do not fit into the categories of Table I. Two taxa are known only at this interval. Two rodent species are represented by one specimen each 


\section{TABLE I}

Principal taxa involved in the faunal turnover at Biohorizon A in the Clark's Fork Basin. Symbols indicate the quality of the biostratigraphic record as explained in the text; - signifies a spotty record. The remaining taxa have records of medium quality. Based on Fig.3.

Appearances: 3

Tetonius steini

Homogalax protapirinus

Hyaenodontid, n. gen. C, sp. 3 -

Terminal disappearances: 8

Phenacodus vortmani

Homogalax n. sp.

Hyaenodontid, n. gen. B, n. sp. -

Hyaenodontid, n. gen. C, sp. 1

Didymictis leptomylus -

Viverravus bowni -

Viverravus n. sp.

Uintacyon rudis

Temporary disappearances: 6

Arctodontomys lineage

Paramys copei -

Phenacodus robustus

Phenacodus brachypternus

Paleonictis occidentalis

Wyolestes apheles

within this interval and have large gaps above and/or below this interval. The records of these four taxa are even more sparse than the "spotty" records. In addition, there are nine instances of change in species names within continuously evolving lineages. Four of these species have good records, two have poor records, and three have records of medium quality up to Biohorizon A and spotty records above it.

Change in species number with time is depicted in Figs. 4 and 5. Since there is little information about absolute time at this level of resolution, we use intervals of stratigraphic thickness to indicate relative time. (The results of this study do not depend on any assumptions about the amount of time represented by each interval.) From Fig.3, we have tabulated standing diversity for each $20-\mathrm{m}$ interval in two ways. The first, more traditional, way is to
TABLE II

Additional taxa with biostratigraphic records especially pertinent to Biohorizon A, as explained in text. Symbols as in Table I; + signifies a record of good quality. Based on Fig.3.

Taxa known only at this interval: 2

Apheliscus wapitiensis

Hyaenodontid, n. gen. A, sp. 2

Taxa represented by one specimen and large gaps above and/or below: 2

Lophioparamys murinus

Microparamys n. sp.

Taxa that change names through anagenetic speciation: 9

Arctodontomys wilsoni - A. nuptus

Hyopsodus loomisi - $H$. latidens +

Haplomylus speirianus - $H$. n. sp.

Hyracotherium grangeri $-H$. n. sp.

Esthonyx spatularius - E. bisulcatus +

Oxyaena gulo - O. intermedia

Arfia shoshoniensis - A. opisthotoma -

Prolimnocyon n. sp. - P. atavus

Miacis deutschi - M. exiguus

count the number of species whose biostratigraphic ranges pass through each interval (Fig.4). Thus, gaps do not count as temporary extinctions. In Fig.4, an early, rapid rise in species richness marks the boundary between the Clarkforkian and Wasatchian. Species richness continues to rise through the early Wasatchian, then drops at Biohorizon $\mathrm{A}$ and declines through the remaining Wasatchian section. The final decline in species richness above $2100 \mathrm{~m}$ is an artifact, reflecting proximity to the top of the section in the Clark's Fork Basin.

In the second tabulation of change in species richness (Fig.5), gaps greater than $200 \mathrm{~m}$ within a species' range count as temporary disappearances and later reappearances. The resulting pattern of change is an exaggerated version of Fig.4, with two exceptions. The decline in species richness above Biohorizon $\mathrm{A}$ is reversed between 1950 and $1995 \mathrm{~m}$ and between 2040 and $2055 \mathrm{~m}$, when, in this view, a number of species "reappear" in the Clark's 


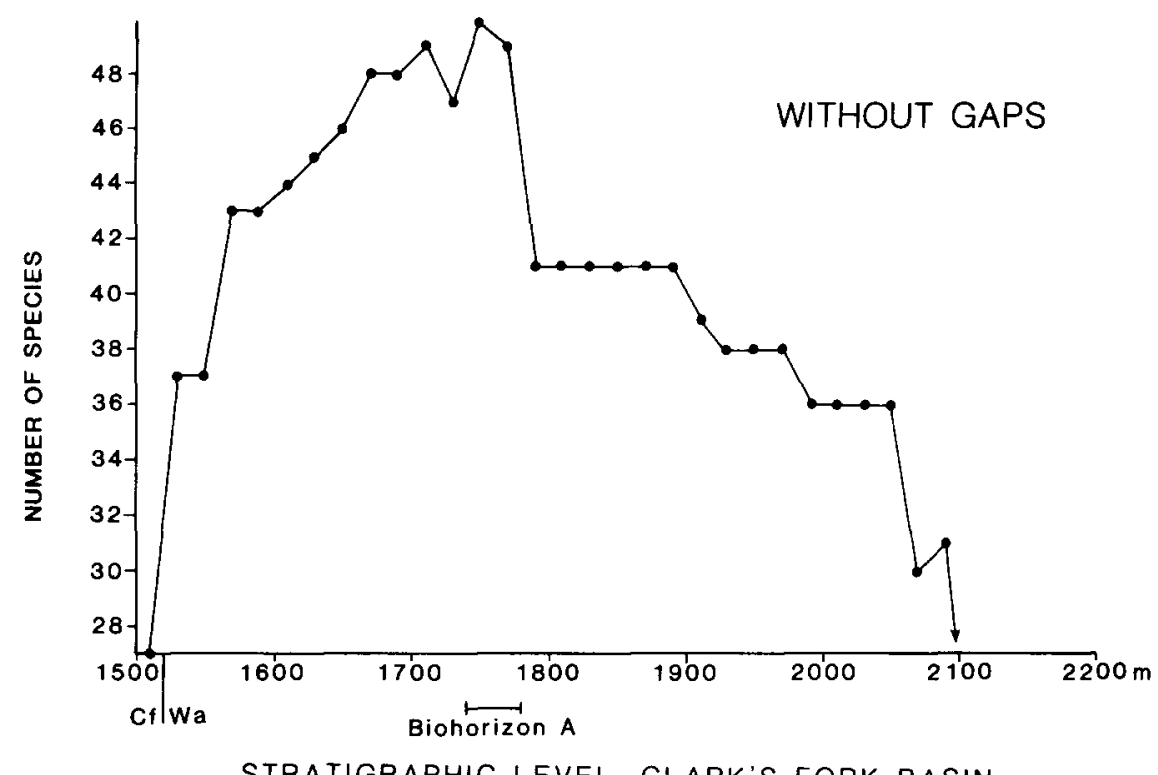

Fig.4. Species richness versus stratigraphic level, compiled for each 20-m interval, based on Fig.3. Gaps within a species range do not count: each species is considered to be present locally from its first to its last records. The highest rates of change occur at the Clarkforkian-Wasatchian boundary and at Biohorizon A. Species number declines above $2100 \mathrm{~m}$ as a result of the loss of exposure and of localities at the top of the section.

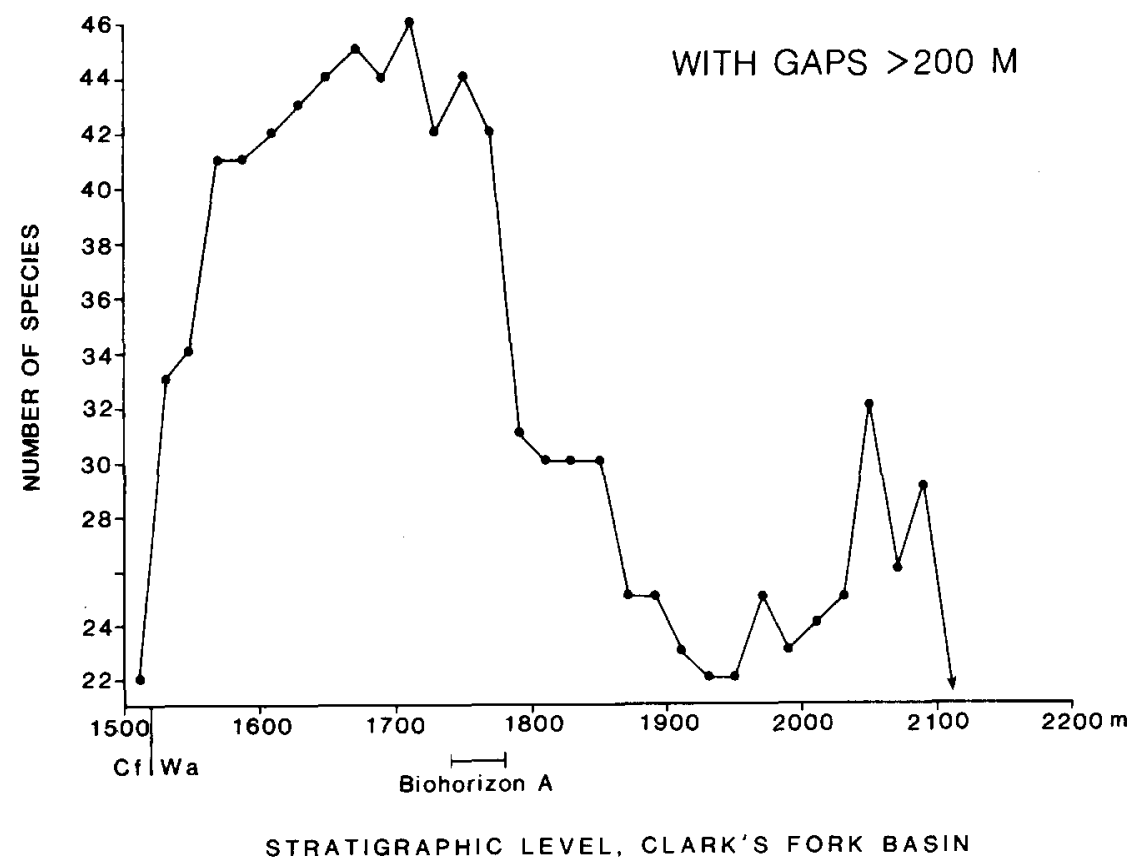

Fig.5. Species richness versus stratigraphic level, with gaps of $200 \mathrm{~m}$ or more counting as temporary disappearances, based on Fig.3. The decline in species number at Biohorizon $\mathrm{A}$ is greater than in Fig.4 because the temporary disappearance of six taxa are now included in the totals. 


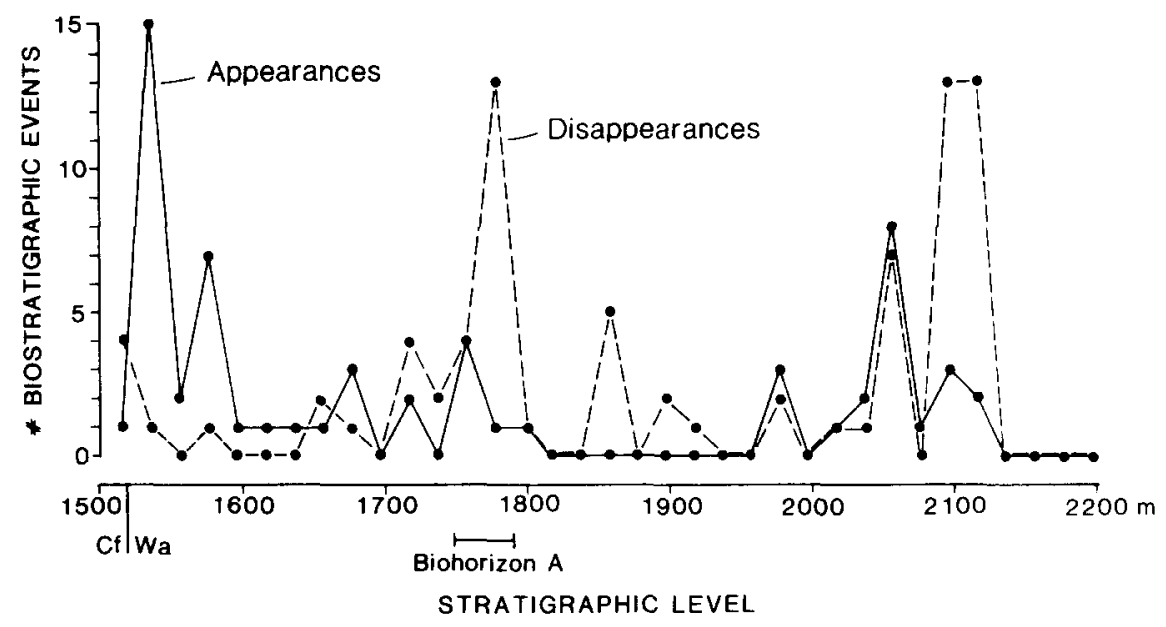

Fig.6. Appearances and disappearances versus stratigraphic level, with gaps of $200 \mathrm{~m}$ or more counting as temporary disappearances with later reappearances. Based on Fig.3.

Fork Basin. According to either Fig.4 or Fig.5, the base of the Wasatchian and Biohorizon A represent periods of greater than usual rate of change in species number.

The number of appearances and disappearances of species for each 20-m interval (Fig.6) best illustrates episodes of faunal turnover. With temporary disappearances and the associated reappearances counting as legitimate biostratigraphic events, the major faunal turnovers are clearly identified as an early episode dominated by appearances (the beginning of the Wasatchian Land Mammal Age) and a later episode dominated by disappearances (Biohorizon A). Before documenting the relationship between faunal turnover and sample size in this record, we present some results of the fine-scale study of Biohorizon A.

\section{Biohorizon A study area}

In the Clark's Fork Basin, the stratigraphic interval of Biohorizon A outcrops principally in an area of about $4 \mathrm{~km}^{2}$ within badland hills. The area is subdivided geographically into several localities; each locality spans part or all of Biohorizon A, which is about $45 \mathrm{~m}$ in total thickness. Seven distinct fossiliferous levels can be identified and traced laterally through much of the area. These levels are the smallest operational units for collection of fossil material on the surface. Figure 7 indicates the stratigraphic spacing and some facies characteristics of the fossiliferous levels at one locality. Each level consists of one or more stratigraphic units; levels range in thickness from 0.3 to $3.0 \mathrm{~m}$, with some lateral variability in thickness within each level. All levels occur in fine-grained floodplain deposits with pervasive pedogenic features.

Intensive surface collecting of all accessible portions of the fossiliferous levels in the Biohorizon A study area yielded approximately 1500 specimens identifiable to genus or species. Species richness (of taxa listed in Fig.3) ranged from 8 to 29 among the collecting levels, with an overall decline from older to younger levels (Fig.8). These data depict, in an enlarged view, the same trend that characterizes the catalogued data (Figs.3-5).

\section{Sedimentary environment of vertebrate fossil assemblages}

The fine-grained, pedogenic facies of the fossiliferous levels in the Biohorizon A study area is the source of virtually all vertebrate remains in the Willwood Formation, both within the Clark's Fork Basin (e.g. Winkler, 1983) and elsewhere within the Bighorn Basin 


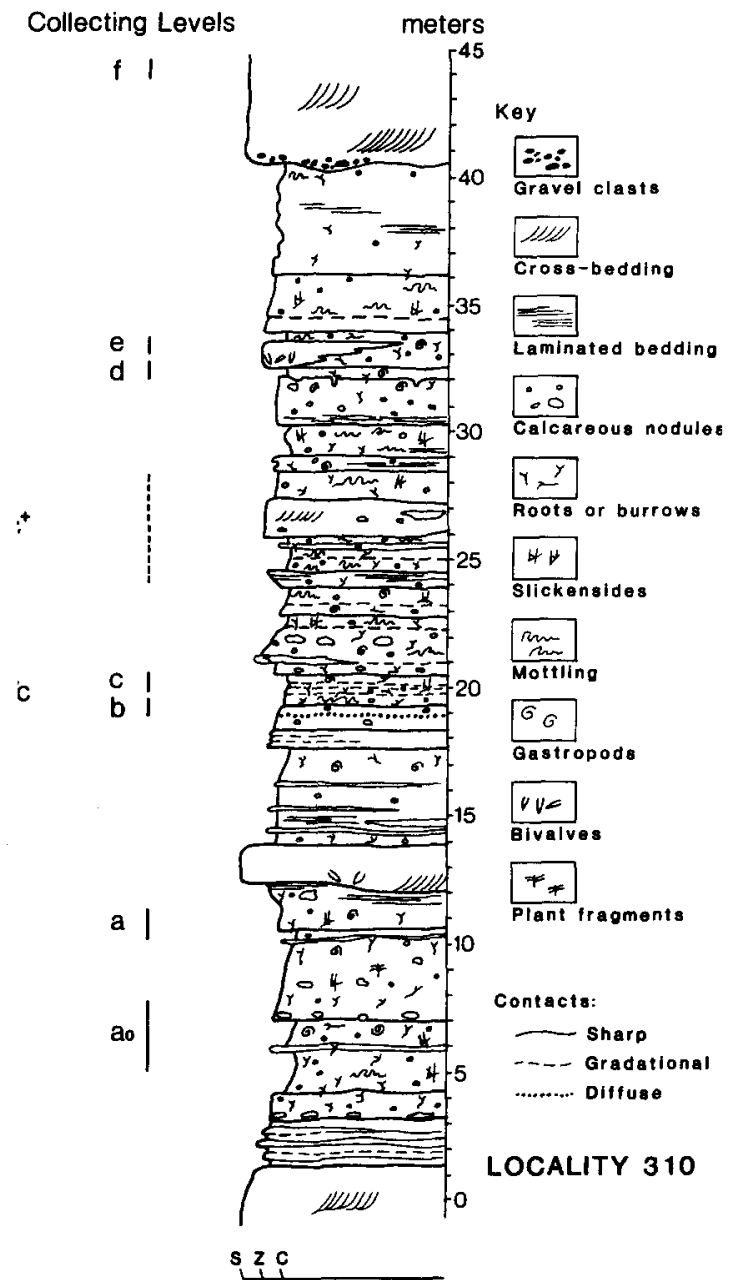

Fig.7. A stratigraphic section through Locality 310, spanning the interval of Biohorizon $A$, with fossiliferous horizons identified by letters. (All horizons but $f$ occur at Locality 310.) The stratigraphic position of $f$ in localities nearby is indicated; at Locality 310 , level $f$ and adjacent floodplain sediments are cut out by a thick erosional sandstone.

(e.g. Bown, 1979; Bown and Kraus, 1981a, b). This facies represents the floodplain environment that was alternately inundated and aerated each year. Thus, differences in faunal composition through time cannot be attributed to different taphonomic processes associated with broadly different sedimentary environments. But, both in the Biohorizon A study area and elsewhere in the Willwood Formation, there is considerable variability within the pedogenic facies in the relative proportions

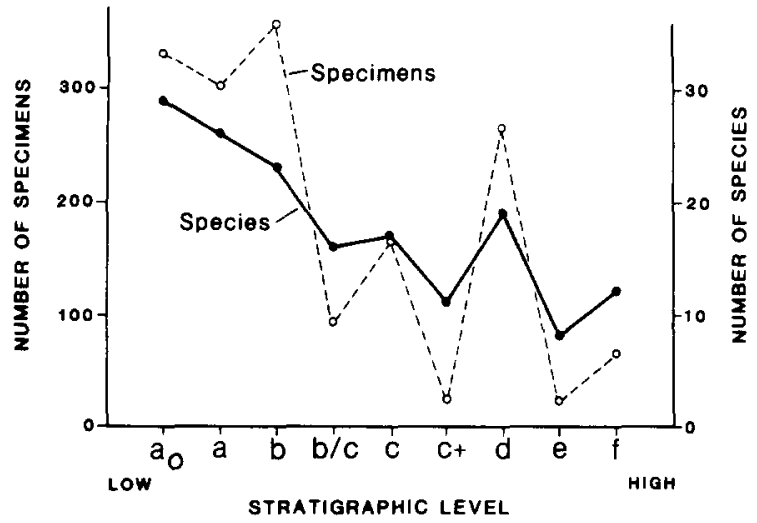

Fig.8. Species richness (solid line) and sample size (number of jaws and teeth recorded as to species, dashed line) for the fossiliferous collecting levels of the Biohorizon A study area. The horizontal axis indicates superpositional order, not measured stratigraphic spacing.

of silt, clay, and sand; in color, texture, and stratification; and in the sizes and kinds of nodules and mottling features. Most of these facies characteristics reflect variation in postdepositional history of the sediments, related to differences in microenvironments and correlated soil-forming processes. Possibly, some of the change in faunal composition is related to changes in paleosol characteristics - a hypothesis that has yet to be fully explored in the Clark's Fork Basin.

\section{Species richness and sample size}

The biological significance of changes in species richness can be evaluated only after sample sizes are taken into account. Figure 8 illustrates how sample size (number of specimens) and species richness covary for the Biohorizon A study area, and Fig.9 illustrates this covariation for the early Wasatchian as a whole. (Figs. 8 and 9 are based on presence or absence in each interval of taxa listed in Fig.3.) In the Biohorizon A study area, sample sizes exhibit a declining trend from older to younger levels (Fig.8), although the decrease in sample size is not as consistent as the decline in species number.

In order to investigate the relationship between sample size and species number in the 


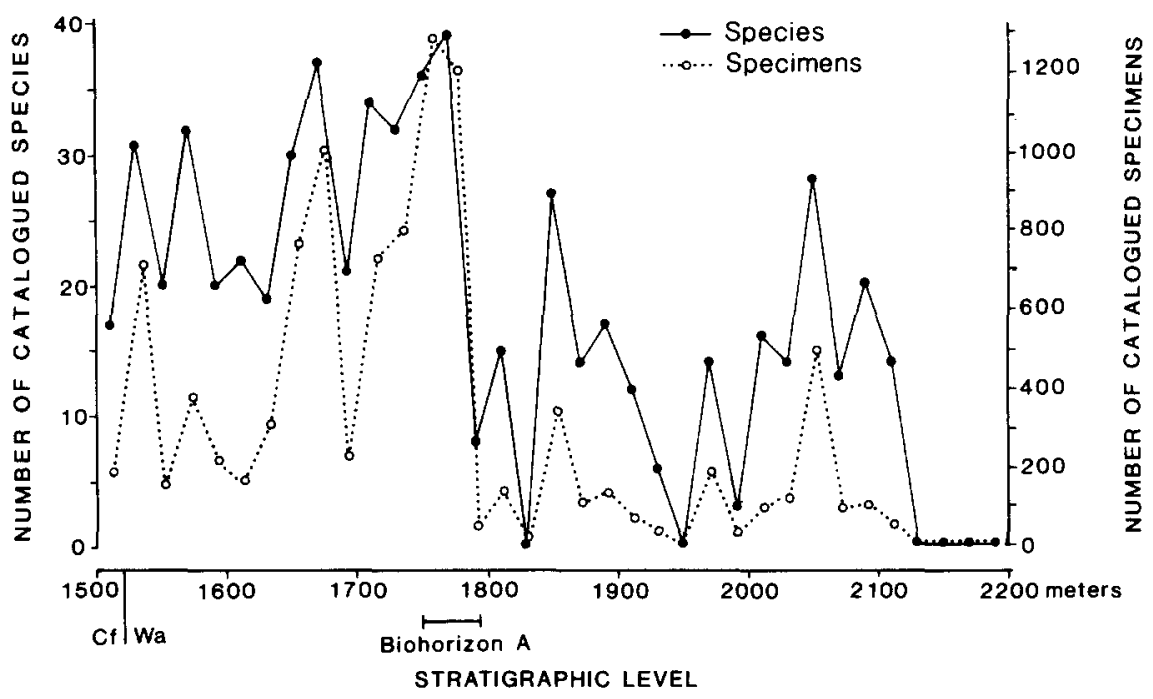

Fig.9. Number of species (solid line) and sample size (dotted line) versus stratigraphic level. Both were compiled for each 20 $m$ interval from the UMMP catalogue as of 1985 .

macroscopic record, it was necessary to tally the number of recorded species for each $20-\mathrm{m}$ interval. Figure 3 does not contain the requisite information, since taxa are represented there by biostratigraphic ranges but are not necessarily recorded in every 20-m interval. (Only taxa with good records are found in every 20-m interval of their biostratigraphic ranges between 1520 and $1755 \mathrm{~m}$; above this level, even the good records show some gaps of $20 \mathrm{~m}$ or more.) Figure 9 depicts, interval by interval, the numbers of specimens and of species recorded for the early Wasatchian. Clearly, peaks in species richness coincide with peaks in sample size, and the drop in species richness at Biohorizon A coincides with a large drop in sample size.

The correlation between root sample size and species number (Fig.10) is high for the combined data sets $(r=0.95)$. (The square root is the appropriate transform for linearizing the scatterplot when the underlying model corresponds to Poisson sampling (Snedecor and Cochran, 1980).) The data from the Biohorizon A study area by themselves exhibit a correlation coefficient of $r=0.94(n=9)$; the UMMP catalogued data alone have a correlation coefficient of $r=0.95(n=29)$, indicating a similarly tight relationship between sample size and species number, despite differences in the methods of collection and documentation.

\section{Discussion}

The high correlation between sample size and species number in Fig.10 indicates that we have no basis for rejecting the following null hypothesis: observed changes in species richness are explained satisfactorily by changes in sample size alone. This relationship is further illustrated in the correspondence between biostratigraphic events (appearances, reappearances, and terminal and temporary disappearances) and sample size (Fig.11). All five peaks in appearances between 1500 and $1995 \mathrm{~m}$ occur in intervals with peaks in specimen number; two minor peaks in specimen number (1800-1815 m, 1840-1855 m) are not associated with appearances. The only reappearances (following temporary disappearances) in Fig.11 occur between 1960 and $1975 \mathrm{~m}$, likewise a local peak in sample size. All of the Wasatchian lineages with "good" records appear in the first peak. Taxa that appear later have records of "medium" or "spotty" quality. Among the species that appear at Biohorizon A, the three principal appearances (Table I) occur within 


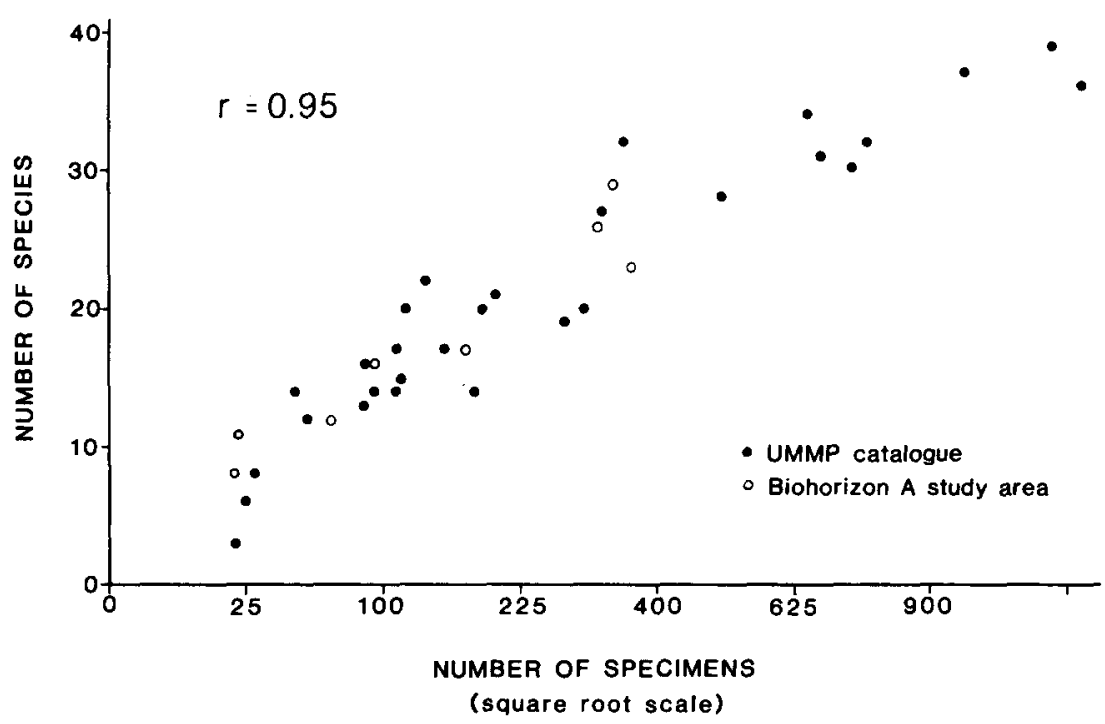

Fig.10. Scatterplot of sample size versus number of species, based on data in Figs.8 and 9. Sample size is represented by the square root of specimen number in order to make the distribution of points more nearly linear. The reported correlation is between species richness and this transform of sample size.

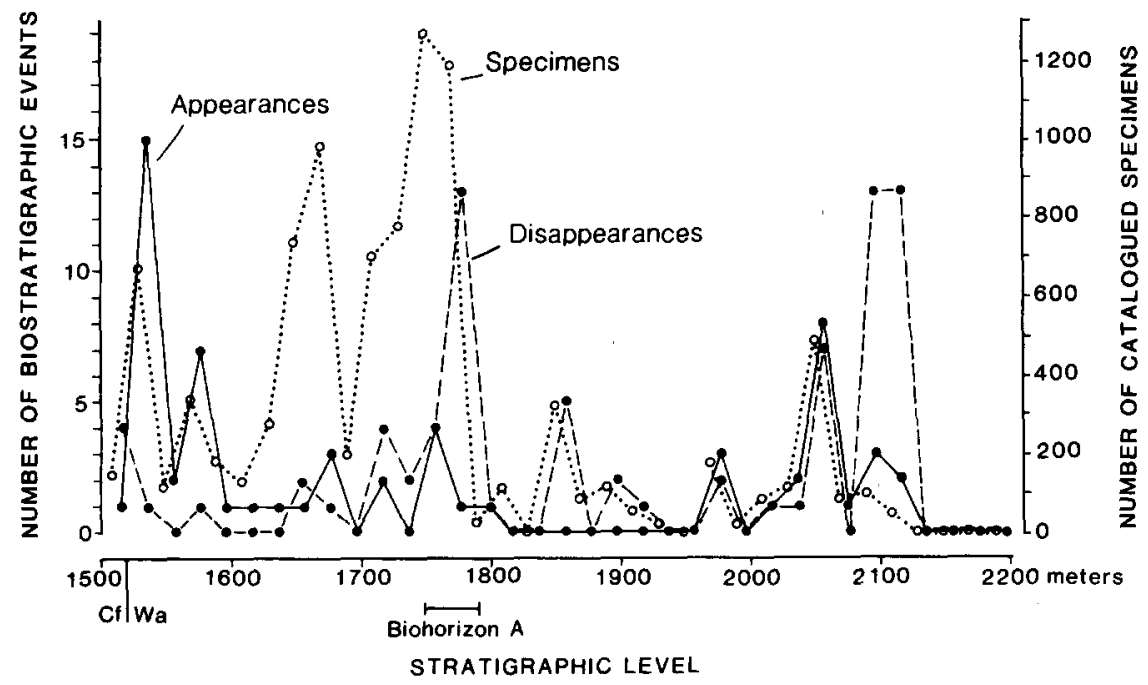

Fig.11. The number of appearances and disappearances (from Fig.6), with gaps of $200 \mathrm{~m}$ or greater counting as temporary disappearances and later reappearances, plotted with sample size (from Fig.9). Data points representing appearances or disappearances are plotted at the interval boundaries. Points representing number of catalogued specimens are plotted in the middle of each interval.

intervals of very high sample sizes. Four additional species are rare or unknown outside this interval (Table II). Thus, the timing of appearances closely tracks peaks in fossil productivity, while the number and taxonomic identities of appearances depend on the prior history of appearances.
Disappearances generally coincide with drops in sample size. The most pronounced example occurs at Biohorizon A. Fourteen species disappear (six? temporarily) when sample size drops from 1027 specimens to 20 specimens in successive $20-\mathrm{m}$ intervals. Nine of the 14 species have poor records even when 
sample sizes are relatively high (below $1780 \mathrm{~m}$ ). The six reappearing taxa occur again in intervals with moderate peaks of sample size. The correlation between disappearances and drops in sample size at and above Biohorizon A indicates that some temporary disappearances are to be expected on the basis of changes in sample size alone. (Whether the disappearance of a particular species is statistically significant can be determined under the assumption of Poisson sampling, as Schankler (1981) demonstrates for phenacodontids.) These reappearances are an example of the "Lazarus effect" (Jablonski, 1986) in a fluvial environment.

The anagenetic speciations that occur at Biohorizon $\mathrm{A}$ in the Clark's Fork Basin (Table II) do not in themselves offer persuasive evidence for a significant faunal change, since the separation between ancestral and descendant species was sometimes determined on the basis of a large gap in the record or by noting the fact of the faunal turnover itself. These speciations are, in any case, arbitrary. All nine lineages that change species name at Biohorizon A exhibit increase in size, as indicated by increased cheek-tooth area. But only in the case of Hyopsodus is size increase a distinct reversal of the trend (size decrease) just below Biohorizon A (Fig.2, Gingerich, 1985). If new taxonomic interpretations were to view any of these changes as cladistic speciation events, the number of appearances and disappearances recorded at Biohorizon $\mathrm{A}$ would be altered, but not the relationship between sample size and species number that we find in these data.

What is the real pattern of appearances and disappearances of species? As the record stands, new taxa of diverse taxonomic and ecological affinities appear early in the Wasatchian. Disappearances occur in pulses and involve species known from the Clarkforkian, along with some of the Wasatchian immigrants (Fig.3). In general, appearances coincide with increases in sample size, and disappearances coincide with decreases in sample size. Common taxa appear early. When sample sizes fall off and later do not rise above moderate values, a number of rare taxa disappear (Fig.11). Some disappearances occur even as sample sizes are increasing (e.g., between 1700 and $1715 \mathrm{~m}$ ). Clearly, substantial changes in faunal composition were occurring through the early Wasatchian record. But since almost $90 \%$ $\left(r^{2}=0.88\right)$ of the apparent pattern can be attributed to variation in sample size (Fig.10), the real pattern of faunal change is little constrained by data.

The apparent pattern is consistent with a number of hypotheses of real faunal change. For example, all appearances (29 species) recorded between 1520 and $1815 \mathrm{~m}$ in Fig.3 could have occurred at the beginning of the Wasatchian, to be detected in pulses as sample sizes rose and fell. According to this hypothesis, had the sample size between 1520 and $1535 \mathrm{~m}$ been increased to 1000 , many of the 29 taxa would have been found, and some new ones as well (Koch, 1987). In the real data, this hypothesis suggests that the appearances are unveiled in pulses because progressively larger sample sizes are required for the rarer taxa.

Another hypothesis is that actual species diversity did not change between 1780 and $1795 \mathrm{~m}$, but rather that the apparent decrease is due solely to the decrease in sample size. Had our samples been enlarged to some 1000 specimens between 1800 and $1815 \mathrm{~m}$, many of the "disappearing" taxa would have been present. Both these expectations derive from the observed relationship between sample size and species number (Fig.10).

This relationship between sample size and species richness is widely known in ecology and paleontology (e.g., May, 1975; Raup, 1975; Tipper, 1979; Koch, 1987). For a specified geographic area and time - that is, for a particular community - larger sample sizes of individuals record ever increasing species richness. The relationship between sample size and species number is typically non-linear; the ratio of species number to sample size is generally greater in small samples than in large ones. If the total number of species present is fixed by assumption, there results the familiar asymptote in species-versus-individuals and rarefaction curves. The ecological 
basis for this pattern is the shape of speciesabundance distributions in nature. Communities have a few common species and many rare ones (Elton, 1927; May, 1975; Koch, 1987; and many others). But these distributions vary in detail, making it difficult to apply a universal standard of correction for sample-size effects in samples from modern and ancient communities.

\section{Fossil productivity}

The striking correlation between sample size and species number raises the important issue of the factors controlling fossil productivity in a stratigraphic section. We suggest three possibilities: area of exposure, taphonomic changes, and ecological changes.

(1) Fossil productivity may be proportional to the area of exposure for any stratigraphic interval. This factor is certainly critical within the Biohorizon A study area: the pattern of badland topography results in a decrease of available exposure up-section. One way to evaluate this hypothesis would be to measure (e.g., by digitization of a base map) the exposure area of selected stratigraphic intervals, then correlate exposure area with the number of catalogued specimens. If the correlation were high, then there would be no basis for inferring a real faunal turnover within the interval currently recognized as Biohorizon $\mathrm{A}$.

(2) Fossil productivity may be controlled by basin-wide changes in sedimentary or climatic processes that affect the preservation of mammalian remains: for instance, change in the rate of sediment accumulation, change in seasonality, or change in the duration of annual floods. In this case, similar changes in fossil productivity should have occurred in the central Bighorn Basin, since it was part of the same climatic and depositional system during the Eocene. Also, such changes should have left some record within the sediments themselves, such as long-term changes through the Wasatchian in the maturity of soils. If this factor were important, then the fact of a faunal turnover would be questionable, although there would be a significant environmental change with far-reaching sedimentological taphonomic effects. It is possible, however, that such environmental changes could cause a faunal turnover as well.

(3) Changes in fossil productivity might be caused by ecological changes in the fauna itself that have taphonomic ramifications, such as changes in the intensity of scavenging. In the case of Biohorizon $\mathrm{A}$, this hypothesis would be most plausible if taxa that appear when fossil productivity is falling can be interpreted reasonably as having caused the drop in productivity (e.g., the appearance of bone-crushing carnivorous species). If this ecological hypothesis were operative, then similar faunal changes elsewhere in the Bighorn Basin and in other basins should be correlated with similar changes in fossil productivity, and no correlated changes in the sediments themselves would be expected.

We cannot conclusively reject any of these factors at present, although there is information that bears on each of them. With regard to the factor of exposure area, the exposures in the Clark's Fork Basin do become restricted and often steeper up-section, resulting in less accessible outcrop area (but possibly more rapid renewal of fossils by erosion) for higher levels. This general observation does not, however, explain the modest increases in sample size above $1800 \mathrm{~m}$.

With regard to the taphonomic factor, the Biohorizon A study area is capped by thick (over $30 \mathrm{~m}$ ), multistoried sandstones (Fig.7), which extend laterally through the Clark's Fork Basin. These sandstones probably account for the initial drop in fossil productivity around $1800 \mathrm{~m}$, since vertebrate remains are rarely found in this facies in the Willwood Formation. Also, these sandstones probably signify a period of widespread erosion, as is associated with the "boundary sandstone" at the base of the Wasatchian around 1500-1515 $\mathrm{m}$ (Kraus, 1980). But above the interval of sandstone there is a return to predominantly fine-grained silts and silty clays, the appropriate facies for vertebrate 
remains. Thus, from the standpoint of sedimentary environments, the sample size should be able to rise (as it does between 1840 and $1815 \mathrm{~m}$ ) to values typical of Biohorizon $\mathrm{A}$ and below.

The pattern of fossil productivity in the central Bighorn Basin bears some similarity to that of the Clark's Fork Basin. Schankler (pers. comm., 1986) reports that at localities around Dorsey and Elk Creeks (Fig.1), sample sizes fall across Biohorizon $\mathrm{A}$ and remain moderately low until the level of Biohorizon B, when sample sizes increase markedly. The decrease at Biohorizon $\mathrm{A}$ is not of the same magnitude as in the Clark's Fork Basin. Bown (pers. comm., 1986) reports that there is a decrease in sample size above Biohorizon A based on localities around Fifteen Mile Creek.

With regard to the ecological factor, the faunal turnover at Biohorizon $\mathrm{A}$ involves the appearance of one carnivorous species and the loss of six others. This pattern neither suggests a mechanism by which faunal change could cause the change in fossil productivity, nor quite rejects the possibility either.

\section{Conclusion}

This study of the early Wasatchian record in the Clark's Fork Basin indicates that changes in sample size through a stratigraphic record may influence the perception of faunal turnover. Although clearly a major change in faunal composition occurred early in the Wasatchian, the peaks and valleys in sample size conceal the timing and rate of this change. Appearances are correlated with peaks in sample size, and disappearances with valleys. We cannot rule out the possibility that the observed pulses of appearances and disappearances, i.e., the faunal turnovers, are an artifact of widely varying sample sizes through the section. Sample size is influenced by a number of ecological and taphonomic factors, including original population sizes and sediment accumulation rates.

The role of sampling in this biostratigraphic record was demonstrated only when sample size was documented along with biostrati- graphic change. Even though sample-size effects are present in the biostratigraphic range chart (Fig.3), in the graphs of change in species richness through time (Figs.4 and 5), and in the record of appearances and disappearances through time (Fig.6), the effects are not immediately evident, since none of these figures document sample size per se. But when changes over time in sample size are plotted together with species richness (Figs. 8 and 9) or appearances and disappearances (Fig.11), the nature of our inferential problem becomes clear. Sample size and species richness should be highly correlated in modern and ancient communities. The confounding situation occurs when large fluctuations in sample size occur over time. In such situations, the record of appearances, disappearances, and species richness is not a reliable indicator of actual faunal change.

Species number and composition vary widely with sample size because so many species are rare. In the record of Biohorizon $A$ in the Clark's Fork Basin, many of the disappearing taxa are carnivorous species. These would have been rare in the original community because of their position in the trophic hierarchy. The herbivorous taxa that disappear have medium to spotty records - low to moderate numbers from stratigraphic levels with moderate to large sample sizes. Whether for taphonomic or ecological reasons, these species are never abundant in the fossil samples. Common species change principally by phyletic evolution. Thus, it is difficult to make a strong case for a faunal turnover in the interval within which Biohorizon A has been located in the Clark's Fork Basin.

Yet we refrain from concluding that Biohorizon A does not exist in the Clark's Fork Basin or anywhere else. The primary historical changes in the data presented here are a rise and fall in fossil productivity. These changes may themselves have chronological and environmental significance as widespread events within the basin of sedimentation. Biohorizon A could be identified more clearly by the collection of additional data, notably above 
$1780 \mathrm{~m}$, so as to enlarge sample sizes to about the values of samples between 1700 and $1775 \mathrm{~m}$. Then, the record would not be free of samplesize effects, but those effects would at least be more comparable from interval to interval.

Episodes of appearance and disappearance of species are, in principle, important ecological and evolutionary events, with historical significance for correlation and for paleoenvironmental analysis as well. If other taphonomic factors are equal (e.g., if there is no substantial change in the facies of fossil assemblages being compared), then appearances and/or disappearances of abundant taxa are less susceptible to the vicissitudes of sampling processes than are appearances or disappearances of rare taxa. Ultimately, the identities of the appearing and disappearing taxa and their possible ecological and co-evolutionary relationships hold the key to the mechanism and significance of faunal turnovers.

\section{Acknowledgments}

We wish to thank the field crews that worked in the Clark's Fork Basin during the summers of 1975-1985 and helped to collect the data presented here. We thank especially Bara Badgley and Jon Pollack for their collections in the Biohorizon A study area and Gregg Gunnell both for collecting fossils and identifying a substantial portion of the collection from the Biohorizon A study area. Fred Bookstein provided important counsel in statistics and improved the manuscript. We thank Kay Behrensmeyer, David Schankler, and Gerald Smith for constructive discussions of both the general subject and the manuscript. Karen Klitz prepared the illustrations. This work was supported in part by NSF grant EAR 83-05931 to CB and by NSF grant BSR 86-07841 to PDG.

\section{References}

Berggren, W. A., McKenna, M. C., Hardenbol, J. and Obradovich, J. D., 1978. Revised Paleogene polarity time scale. J. Geol., 86: 67-81.

Bown, T. M., 1979. Geology and mammalian paleontology of the Sand Creek Facies, lower Willwood Formation
(Lower Eocene), Washakie County, Wyoming. Mem. Geol. Surv. Wyo., 2, 151 pp.

Bown, T. M. and Kraus, M. J., 1981a. Lower Eocene alluvial paleosols (Willwood Formation, northwest Wyoming, U.S.A.) and their significance for paleoecology, paleoclimatology, and basin analysis. Palaeogeogr., Palaeoclimatol., Palaeoecol., 34: 1-30.

Bown, T. M. and Kraus, M. J., 1981b. Vertebrate fossilbearing paleosol units (Willwood Formation, Lower Eocene, northwest Wyoming, U.S.A.): Implications for taphonomy, biostratigraphy, and assemblage analysis. Palaeogeogr., Palaeoclimatol., Palaeoecol., 34: 31-56.

Elton, C., 1927. Animal Ecology. Methuen, London, 207 pp.

Gingerich, P. D., 1980. Evolutionary patterns in early Cenozoic mammals. Annu. Rev. Earth Planet. Sci., 8: 407-424.

Gingerich, P. D., 1982. Time resolution in mammalian evolution: sampling, lineages, and faunal turnover. In: Proc. Third North Am. Paleontol. Conv., Montreal, 1982, 1: 205-210.

Gingerich, P. D., 1983a. Paleocene-Eocene faunal zones and a preliminary analysis of Laramide structural deformation in the Clark's Fork Basin, Wyoming. In: Wyo. Geol. Assoc. 34th Annu. Field Conf., 1983, Guidebook, pp. 185-195.

Gingerich, P. D., 1983b. Systematics of early Eocene Miacidae (Mammalia, Carnivora) in the Clark's Fork Basin, Wyoming. Univ. Mich. Contrib. Paleontol., 26: 197-225.

Gingerich, P. D., 1985. Species in the fossil record: concepts, trends, and transition. Paleobiology, 11: 27-41.

Gingerich, P. D., 1986. Early Eocene Cantius torresi oldest primate of modern aspect from North America. Nature, 320: 319-321.

Gingerich, P. D. and Gunnell, G. F., 1979. Systematics and evolution of the genus Esthonyx (Mammalia, Tillodontia) in the early Eocene of North America. Univ. Mich. Contrib. Paleontol., 25(7): 125-153.

Gunnell, G. F., 1985. Systematics of early Eocene Microsyopinae (Mammalia, Primates) in the Clark's Fork Basin, Wyoming. Univ. Mich. Contrib. Paleontol., 27(2): 51-71.

Ivy, L. D., 1982. Systematics and biostratigraphy of the earliest North American Rodentia (Mammalia), latest Paleocene and early Eocene of the Clark's Fork Basin, Wyoming. Thesis, Univ. Michigan (unpublished).

Jablonski, D., 1986. Causes and consequences of mass extinctions: a comparative approach. In: D. K. Elliott (Editor), Dynamics of Extinction. Mus. North. Ariz. Press, Flagstaff, Ariz., pp. 183-229.

Kitchell, J. A. and Carr, T. R., 1985. Nonequilibrium model of diversification: faunal turnover dynamics. In: J. W. Valentine (Editor), Phanerozoic Diversity Patterns: Profiles in Macroevolution. Princeton Univ. Press, Princeton, N.J., pp. 277-309.

Koch, C. F., 1987. Prediction of sample size effects on the measured temporal and geographic distribution patterns of species. Paleobiology, 13: 100-107.

Kraus, M. J., 1980. Genesis of a fluvial sheet sandstone, Willwood Formation, northwest Wyoming. In: P. D. 
Gingerich (Editor), Early Cenozoic Paleontology and Stratigraphy of the Bighorn Basin, Wyoming. Univ. Mich. Pap. Paleontol,, 24: 87-94.

May, R., 1975. Patterns of species abundance and diversity. In: M. L. Cody and J. M. Diamond (Editors), Ecology and Evolution of Communities. Belknap Press (Harvard Univ.), Cambridge, Mass, pp. 81-120.

Olson, E. C., 1980. Taphonomy: its history and role in community evolution. In: A. K. Behrensmeyer and A. P. Hill (Editors), Fossils in the Making. Univ. Chicago Press, Chicago, Ill., pp. 5-19.

Raup, D. M., 1975. Taxonomic diversity estimation using rarefaction. Paleobiology, 1: 333-342.

Schankler, D. M., 1980. Faunal zonation of the Willwood Formation in the Central Bighorn Basin, Wyoming. In: P. D. Gingerich (Editor), Early Cenozoic Paleontology and Stratigraphy of the Bighorn Basin, Wyoming. Univ. Mich. Pap. Paleontol., 24: 99-110.

Schankler, D. M., 1981. Local extinction and ecological reentry of early Eocene mammals. Nature, 293: 135-138.
Sepkoski, J. J., Jr., 1981. A factor analytic description of the Phanerozoic marine fossil record. Paleobiology, 7 : $36-53$.

Snedecor, G. W. and Cochran, W. G., 1980. Statistical Methods. Iowa State Univ. Press, Ames, Iowa, 507 pp. (7th ed.).

Tipper, J. C., 1979. Rarefaction and rarefiction: the use and abuse of a method in paleoecology. Paleobiology, 5: $423-434$.

Vrba, E. S., 1985. Environment and evolution: alternative causes of the temporal distribution of evolutionary events. S. Afr. J. Sci., 81: 229-236.

Webb, S. D., 1984. On two kinds of rapid faunal turnover. In: W. A. Berggren and J. A. Van Couvering (Editors), Catastrophes and Earth History. Princeton Univ. Press, Princeton, N.J., pp. 417-436.

Winkler, D. A., 1983. Paleoecology of an early Eocene mammalian fauna from paleosols in the Clark's Fork Basin, northwestern Wyoming (U.S.A.). Palaeogeogr., Palaeoclimatol., Palaeoecol., 43: 261-298. 